Stripping Volatile Organic Compounds and Petroleum Hydrocarbons From Water by Tray Aeration

David F. LaBranche and M. Robin Collins 
Abstract: Volatile organic compounds (VOCs) and petroleum products are ubiquitous groundwater contaminants. Petroleum products, e.g., diesel fuel, contain a wide array of volatile, semivolatile, and long-chain hydrocarbon compounds. This research sought to determine whether air stripping can provide a site-specific treatment solution for petroleum-contaminated groundwaters and to document the abilities and limitations of tray-type (ShallowTray) air stripping technology. Full factorial experimental trials were conducted to determine the influence of inlet water flow rate and temperature on trichloroethylene (TCE), perchloroeth- ylene (PCE) and total petroleum hydrocarbon (TPH) removal. As expected, TPH removal controlled air stripper performance, and liquid temperature affected removal more than flow rate. The mass transfer rate of TCE and PCE from water to air was controlled by the compound's volatility, while the TPH mass transfer rate was controlled by the compound's concentration gradient. Results indicate that economical air stripping of VOC and TPH compounds can be achieved using low liquid flow rates (20-75 L/min) and medium liquid temperatures $\left(16-28^{\circ} \mathrm{C}\right)$ in tray-type air strippers.

\section{How to get copies of CRREL technical publications:}

Department of Defense personnel and contractors may order reports through the Defense Technical Information Center:

DTIC-BR SUITE 0944

8725 JOHN J KINGMAN RD

FT BELVOIR VA 22060-6218

Telephone 18002253842

E-mail help@dtic.mil

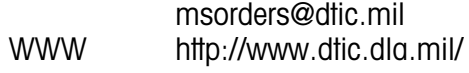

All others may order reports through the National Technical Information Service:

NTIS

5285 PORT ROYAL RD

SPRINGFIELD VA 22161

Telephone 17034874650

17034874639 (TDD for the hearing-impaired)

E-mail orders@ntis.fedworld.gov

WWW http://www.fedworld.gov/ntis/ntishome.html

A complete list of all CRREL technical publications is available from:

USACRREL (CECRL-TL)

72 LYME RD

HANOVER NH 03755-1290

Telephone 16036464338

E-mail techpubs@crrel.usace.army.mil

For information on all aspects of the Cold Regions Research and Engineering Laboratory, visit our World Wide Web site: http://www.crrel.usace.army.mil 
Special Report 97-6

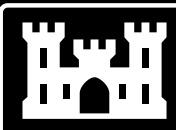

US Army Corps

of Engineers $\circledast$

Cold Regions Research \&

Engineering Laboratory

\section{Stripping Volatile Organic Compounds and Petroleum Hydrocarbons From Water by Tray Aeration}

David F. LaBranche and M. Robin Collins 


\section{PREFACE}

This report was prepared by David F. LaBranche, Master's candidate, in the Civil Engineering Department (currently a Major in the U.S. Army) and M. Robin Collins, Associate Professor of Civil Engineering at the University of New Hampshire (UNH). Correspondence should be addressed to M.R. Collins, Department of Civil Engineering, University of New Hampshire, Durham, New Hampshire 03824-3591.

The research described in this report was supported by the Department of the Army through the U.S. Army Cold Regions Research and Engineering Laboratory (CRREL), Hanover, New Hampshire, and by North East Environmental Products, Inc., West Lebanon, New Hampshire. Additional support was also provided by the Environmental Research Group of UNH. The authors thank Dr. I.K. Iskandar, and the analytical chemistry personnel at CRREL for their guidance and assistance.The authors also thank Dr. Iskandar and Daniel J. McKay for technically reviewing the manuscript of this report.

The contents of this report are not to be used for advertising or promotional purposes. Citation of brand names does not constitute an official endorsement or approval of the use of such commercial products. 


\section{CONTENTS}

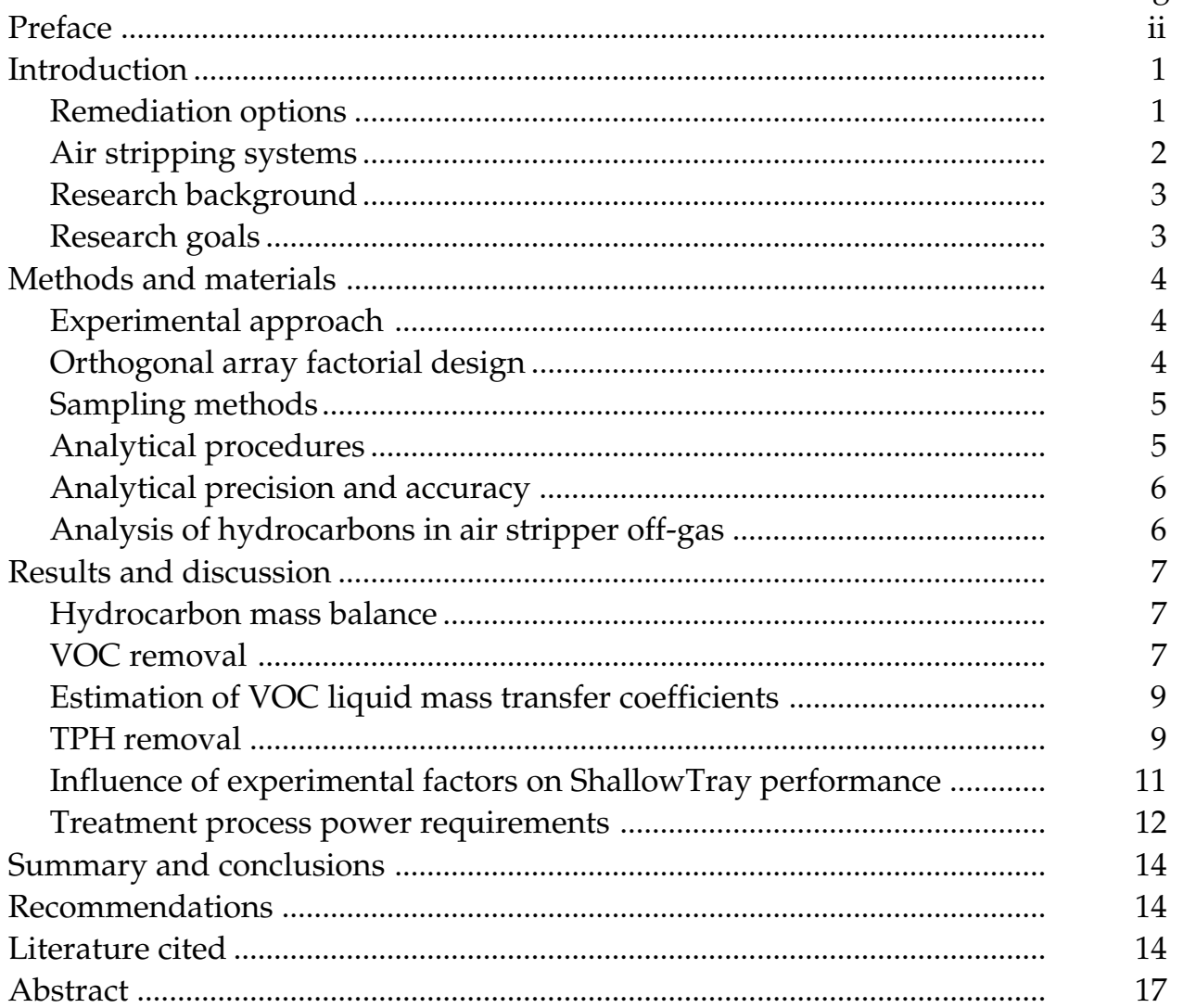

\section{ILLUSTRATIONS}

\section{Figure}

1. Air stripping process .............................................................................. 2

2. Process flow diagram for ShallowTray medium temperature air stripping experiment ...................................................................

3. TCE pre-and post-treatment concentrations for all experimental trials

4. PCE pre- and post-treatment concentrations for all experimental trials

5. TPH pre- and post-treatment concentrations for all experimental trials

6. TPH stripping performance at three liquid temperatures and two flow rates 
7. Predicted response surface for TPH removal vs. liquid temperature and flow rate ......................................................................... 11

8. Stripping and heating power requirements vs. liquid flow rate, ShallowTray medium temperature process....

\section{TABLES}

\section{Table}

1. Concentration, solubility and Henry's law constants of primary contaminants in source water for medium temperature air stripping experiments ...................................................................

2. Orthogonal array of experimental trials and trial sequence ................. 5

3. Nested design of sampling and analysis for ShallowTray medium temperature air stripping experiment ........................... 5

4. VOC removals by ShallowTray air stripping achieved at three liquid temperatures and two liquid flow rates ............................... $\quad 8$

5. Estimate of mass transfer coefficients for ShallowTray stripping of TCE and PCE at three liquid temperatures

5

6. Contribution of experimental factors to ShallowTray stripping

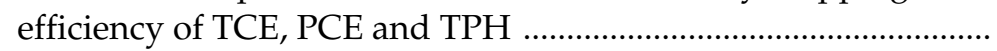




\title{
Stripping Volatile Organic Compounds and Petroleum Hydrocarbons From Water by Tray Aeration
}

\author{
DAVID F. LABRANCHE AND M. ROBIN COLLINS
}

\section{INTRODUCTION}

Contaminated groundwater is perhaps the most ubiquitous target of hazardous waste remediation efforts in the United States. Volatile organic chemicals (VOCs) and petroleum products have been consistently identified as the most common groundwater contaminants, particularly at Department of Defense sites. As of September 1991, the Department of Defense (DOD) had identified 17,660 sites with potential hazardous waste contamination of soil or groundwater (Rose 1994). Of these, the DOD estimates that 7,313 sites will require remediation. According to a 1992 General Accounting Office (GAO), the federal government faces nearly $\$ 200$ billion in cleanup costs for DOD and Department of Energy (DOE) sites before the end of the decade. Effective and efficient treatment methods are needed to meet this cleanup challenge (U.S. GAO 1992).

Because of the highly mechanized nature of DOD operations, VOCs and a wide variety of petroleum fuels are used and stored in large quantities at nearly every installation. The most prevalent $V O C$ groundwater contaminants at DOD sites are chlorinated solvents (Rose 1994), which are generally denser than water and only slightly soluble. The most prevalent petroleum contaminants at DOD sites are gasoline (including aviation fuel) and diesel fuel, both of which are lighter than water and insoluble (U.S. EPA 1990). Experience at numerous groundwater remediation sites has shown that despite the density differences between VOCs and petroleum hydrocarbons, they are frequently found mixed in the aquifer due to sorption to soils and water table fluctuations. Treatment processes employed to remediate the groundwater must be capable of handling con- taminants that have a wide range of physical and thermodynamic properties.

\section{Remediation options}

Currently, the most promising and preferred method for fully remediating VOCs and petroleum hydrocarbons from groundwater is bioremediation (Rose 1994). Bioremediation schemes, however, operate most efficiently when the concentration in the water of the most common VOCs and petroleum hydrocarbons (the biological substrate) is relatively dilute. The common VOC and petroleum contaminants are only slightly to moderately biodegradable, having optimal $\mathrm{BOD}_{5} /$ COD ratios $<0.40$ (U.S. EPA 1985). High concentrations $(\leq 1 / 3$ rd of solubility values) of VOCs in water are easily reduced by many methods. The cost-effective method chosen most often is to pump the VOC contaminated groundwater to the surface then transfer the contaminants to a solid phase adsorber by air stripping. Recent research indicates that high concentrations of petroleum hydrocarbons in groundwater can also be effectively reduced by pumping followed by aboveground treatments such as solid-phase adsorption (Borden and Kao 1992). The dominant hydrocarbons that make up gasoline, i.e., benzene, toluene, ethylbenzene and the xylenes (BTEX), are aromatics, which are highly volatile and amenable to air stripping due to their high Henry's law constants (API 1983). However, the dominant hydrocarbons found in diesel fuel are paraffins (API 1976). These hydrocarbons are much less volatile than BTEX, having large molecules with molecular weights ranging from 142.3 (decane) to 394.8 (octacosane). Long-chain hydrocarbons (paraffins and larger) are nearly insoluble in water and typically exist in both a soluble and 
separate phase as aqueous contaminants (API 1976). This separate phase frequently requires another removal process in remediation schemes.

Separate phase or "free product" petroleum can be removed by basic oil/water separators, which are readily available and relatively inexpensive. High performance oil/ water separators are available that can theoretically remove enough separate phase and soluble petroleum to meet most state discharge permits (approximately $1 \mathrm{mg} / \mathrm{L}$ ), but they are very expensive and may employ materials which would be damaged by exposure to VOCs like chlorinated solvents (Hackman 1978).

Liquid-phase adsorption of petroleum hydrocarbons is a common industrial application, and has been compared favorably to vapor-phase hydrocarbon adsorption (API 1983). However, neither liquid nor vapor phase adsorption is the best method for all petroleum hydrocarbon removal applications. Sorption sites on activated carbon can be limited during liquid-phase adsorption by aqueous suspended solids (API 1983). Vapor-phase adsorption can have a significant cost advantage when treating highly contaminated groundwaters, because it allows lower contaminant loading rates and minimizes inorganic loading to the adsorbent, which in turn maximizes its useful life (API 1983).

\section{Air stripping systems}

Air stripping is the most commonly used liquid-to-gas mass transfer method for VOCs. Air stripping of BTEX compounds has been widely successful, but only steam stripping and high temperature air stripping (HTAS) have been considered feasible for treating less volatile organics like long-chain hydrocarbons (Fleming 1989, U.S. EPA 1991). Inside the most common type of air strippers, i.e., packed towers, high liquid surface area is created by pumping water to the top of a hollow tower and allowing it to trickle over a dumped packing inside. The water spreads over the packing as it flows downward, creating a thin, high surface area film. The thin films on the packing are met by a counter-current flow of air blown in from the bottom of the tower.

During the past five years, compact, low-profile air strippers have gained increasing acceptance and now represent more than half of the air strippers used at new remediation sites (Lamarre 1993). The most common style of low profile air stripper is the tray-type unit in which a shallow layer of water is allowed to flow along one or more trays as noted in Figure 1. Air is blown through hundreds of holes in the bottom of the trays to generate a froth of bubbles-a large mass transfer surface area where the contaminants are volatilized. In the tray-type, low-profile aeration system the air performs two functions: 1 ) creating the interfacial surface area (created by the packing in a packed tower) and 2) volatilizing the contaminants. This feature of the tray-type air stripper is advantageous when treating waters that contain high concentrations of soluble inorganics. In the tray-type unit, metal oxide precipitates are easily cleaned from the smooth stain- 
Table 1. Concentration, solubility and Henry's law constants of primary contaminants in source water for medium temperature air stripping experiments.

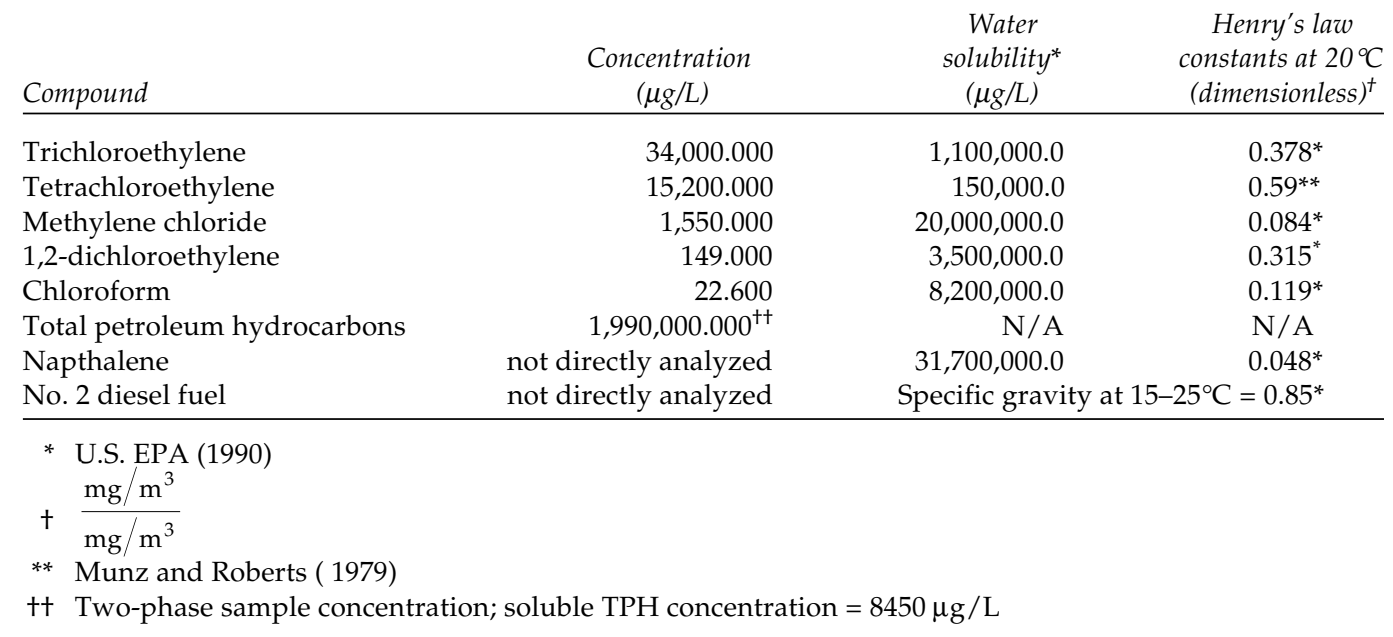

less-steel trays, whereas in a packed tower they can precipitate on the packing, causing fouling and short circuiting. Similarly, long-chain hydrocarbons tend to sorb to solid surfaces, potentially fouling packed tower media. The vigorous bubbling action in a tray-type stripper scours the unit's interior during operation, usually limiting precipitation and biofilm development (Lamarre 1993).

\section{Research background}

This research grew out of the need to remove a variety of VOCs and diesel-range hydrocarbons from approximately 30,000 L (8000 gal.) of water at CRREL. This was contained in an ice drilling test facility (IDTF) for approximately 20 years. The IDTF is no longer used and is essentially an open-head storage for this contaminated water. GC/MS analysis of individual contaminants indicated that the contaminants had been moderately weathered. Consequently, the contaminated water source provided an excellent opportunity for a realistic treatment study using a homogeneous, weathered mix of dense and light aqueous contaminants which was relatively free of particulate and biological interferences. The primary contaminants in the water source and their critical properties are listed in Table 1. Under a Cooperative Research and Development Agreement between CRREL and a local business (North East Environmental Products, Inc.), a commercial, traytype air stripper was made available for treating this contaminated water.

\section{Research goals}

The research described in this report sought to evaluate the potential for transferring VOCs and long-chain petroleum hydrocarbons from a contaminated water to the vapor phase using a traytype air stripper. The goal was to achieve high contaminant removal rates as economically as possible, using only moderate liquid temperatures and simple, commercially available equipment. The tray-type air stripper used is known as ShallowTray (North East Environmental Products, Inc., West Lebanon, N.H.). A ShallowTray unit was chosen because of its resistance to fouling and lowprofile size (approx. height, $2.12 \mathrm{~m}$ ). The unit was operated inside a large shed, allowing constant temperature control of the treatment process.

The specific goals were to:

1. Measure and analyze the treatment performance of concurrently stripping VOCs and petroleum hydrocarbons from water by ShallowTray aeration as a function of liquid temperature and flow rate.

2. Measure and analyze the operating costs of this treatment.

3. Using empirical data, derive formulas that could predict ShallowTray stripping efficiency as a function of liquid temperature and flow rate, and as a function of power consumption per volume of water treated.

4. Recommend the suitability of this process to remediate similar contamination sources.

Stripping performance was measured by determining the influent and effluent concentrations 
of two VOCs, trichloroethylene (TCE) and tetraor perchloroethylene (PCE), and diesel range hydrocarbons as total petroleum hydrocarbons (TPH).

\section{METHODS AND MATERIALS}

\section{Experimental approach}

The experimental approach consisted of nine separate trial runs during which liquid temperature and flow rate were varied to determine their effect on stripping efficiency of TCE, PCE and diesel hydrocarbons (as TPH). Field data of air strippers treating a wide variety of aqueous contaminants indicates that a) liquid flow rate, $b$ ) detention time, c) temperature, and d) the contaminants' physical and thermodynamic properties are the factors that control stripping efficiency (U.S. EPA 1990). The experimental variables evaluated the effects of (a), (b) and (c), while effects of (d) were estimated by analyzing three contaminants with widely differing properties.

The treatment process consisted of 1) pumping the contaminated water in $1100-$ to $2000-\mathrm{L}$ batches from the ice well, 2) pumping it through an oil/water separator to a storage (equalization) tank, 3) treatment in the ShallowTray air stripper, and 4) storage in another tank for testing prior to recycling to the ice well. The process flow diagram is depicted in Figure 2. Water was pumped from the ice well by a $375-\mathrm{W}$ (1/2-hp), 10-cm (4in.) diameter deep well pump of standard design (Goulds Pumps, Inc., Seneca Falls, N.Y.). The oil/ water separator (HydroFlo Technologies, Inc., Wheaton, Ill.) was of coalescing plate type and

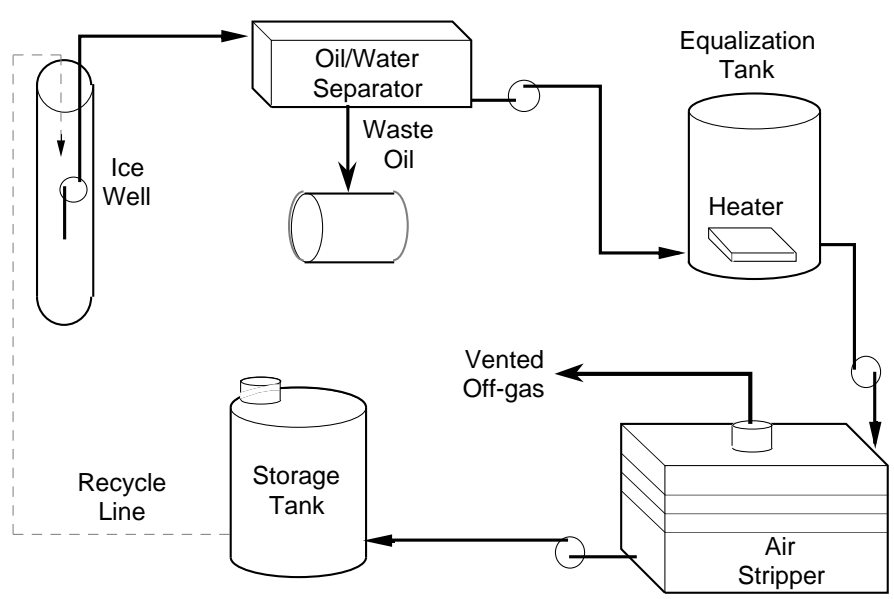

Figure 2. Process flow diagram for ShallowTray medium temperature air stripping experiment. capable of flow rates up to $57 \mathrm{~L} / \mathrm{min}$ (15 gpm). The open-head, cylindrical equalization tank was of high-density polyethylene (HDPE) and fitted with a small circulation pump and a low temperature, TFE-encased heating element of 6000$\mathrm{W}$ capacity. The tank also contained a double layer of 20-mm hollow polypropylene balls to reduce heat loss and limit volatilization. The air stripping unit was a ShallowTray Model 2631, a stainless steel, tray-type or "sieve plate" aerator equipped with three modular trays (Fig. 1). The unit is capable of accepting a fourth aeration tray and treating flows up to $340.2 \mathrm{~L} / \mathrm{min}$ (90 gpm). Ambient air was supplied to the unit at a rate of $17-20 \mathrm{~m}^{3} / \mathrm{min}(600-700 \mathrm{cfm})$. Treated water from every three trials was stored in a 3785 L (1000 gal.) closed-head HDPE tank until preliminary analysis indicated that VOC or TPH concentrations were within discharge permit limits. TPH concentrations from several trials met discharge standards, but the concentration of the mixed, treated effluent from the storage tank did not, resulting in all treated water being recycled to the ice well. Recycled water was drained back to the ice well so as to minimize turbulent mixing.

\section{Orthogonal array factorial design}

The efficiency of factorial design principles allowed all research goals to be met, within accepted standards of statistical significance, using only nine separate experiments or trials. Air stripping efficiency in removing TCE, PCE, and TPH from the ice well water was evaluated by conducting two initial or "equilibrium" trials followed by seven main trials; results from one of the equilibrium trials were used with the seven main trials to form a final factorial array of eight trials. The trial factor levels and experimental conditions were selected so as to create an orthogonal array, which allows statistical information to be gathered about the main variables and their interactions (Ross 1985). The data statistic generated from each trial was removal of TCE, PCE or TPH expressed as a percentage, or as a ratio of effluent concentration over influent concentration $\left(C_{\mathrm{e}} / C_{\mathrm{o}}\right)$. Concentrations were measured on a mass-per-liquid-volume basis. The trial factors selected as independent variables were liquid flow rate and liquid temperature. The range for varying each factor was determined from known physical and thermodynamic properties of the compounds involved, and documented 
Table 2. Orthogonal array of experimental trials and trial sequence.

\begin{tabular}{cccc} 
Trial & $\begin{array}{c}\text { Temperature } \\
(\text { Factor } A) \\
\left({ }^{\circ} \mathrm{C}\right)\end{array}$ & $\begin{array}{c}\text { Flow rate } \\
(\text { Factor B) } \\
(\mathrm{L} / \mathrm{min})\end{array}$ & $\begin{array}{c}\text { Random } \\
\text { sequence } \\
\text { of trials }\end{array}$ \\
\hline 1 & 8.89 & 18.9 & 5 \\
2 & & & \\
(Equilibrium A) & 8.89 & 75.7 & 1 \\
3 & 8.89 & 75.7 & 4 \\
4 & 15.56 & 18.9 & 7 \\
5 & 15.56 & 75.7 & 8 \\
(Equilibrium B) & 22.20 & 18.9 & 2 \\
6 & 22.20 & 18.9 & 3 \\
7 & 22.20 & 18.9 & 9 \\
8 & 22.20 & 75.7 & 6 \\
\hline
\end{tabular}

air stripping performance conditions (U.S. EPA 1991).

A full factorial design of six experimental trials results from varying temperature at three levels and flow rate at two levels. This design provided an experimental resolution level of 4 , meaning all main effects and factor interactions can be statistically estimated by analysis of variance (ANOVA). The six-trial design was made more robust by conducting two additional trials, duplicates of trials that were excessively variable or critical to predicting performance. The researcher chose to repeat the trials conducted at the factor level extremes (trial 1 at $8.89^{\circ} \mathrm{C}$ with $75.7 \mathrm{~L} / \mathrm{min}\left[48^{\circ} \mathrm{F} / 20 \mathrm{gpm}\right]$, and trial 3 at $22.2^{\circ} \mathrm{C}$ with $\left.18.9 \mathrm{~L} / \mathrm{min}\left[72^{\circ} \mathrm{F} / 5 \mathrm{gpm}\right]\right)$. The two pairs of replicated trials were treated as simple duplicates and used to determine experimental variability between trials. The array of all trials, equilibrium and main, and the actual random sequence in which they were conducted is shown in Table 2. Note that the table indicates the equilibrium conditions and that equilibrium trial A results were used in the final $\mathrm{L}_{8}$ array. The equilibrium trials were conducted with special attention to achieving uniform contaminant concentration and temperature in the equalization tank. The experience gained in these trials was used to perfect the process flow as well as the sampling and analysis methods. The results of the first group of four trials (not including equilibrium trial B) formed an $\mathrm{L}_{4}$ array. Statistical analysis of these results confirmed that stripping performance for this source water was controlled by TPH removal and that TPH removal was controlled by liquid temperature, not flow rate. Liquid temperature was therefore varied at a third level in the remaining trials.

\section{Sampling methods}

Two types of aqueous samples, VOC and TPH, were collected and analyzed during each trial. A nested design of eight trials, six samples per trial, and three analyses per sample was performed. The samples collected and analyzed for a typical trial of the $8 \times 6 \times 3$ design is shown in Table 3 . More than 300 analyses were performed to produce statistically reliable data from the eight main trials in this experiment. To determine sampling variability and analytical precision, triplicate influent and triplicate effluent samples were collected, each analyzed in triplicate. Sampling periods were spaced 2.8 minutes apart at the $75.7-\mathrm{L} /$ min flow rate, and 11.2 minutes apart at the 18.9 $\mathrm{L} / \mathrm{min}$ flow rate. These periods are equal to the detention times under plug-flow conditions, and were used so that approximately the same slug of influent water was sampled at the effluent.

\section{Analytical procedures \\ VOC samples were collected in EPA-cleaned} 40-mL vials with Teflon-lined septa (Eagle-Picher Environmental Science and Technology, Miami, Okla.). Samples were stored at $4^{\circ} \mathrm{C}$ and analyzed within six days. Analysis was by headspace gas chromatography (HS/GC) techniques and a photoionization detector as presented by Hewitt et al. (1992). The gas chromatograph used was a Photovac Model $10 \mathrm{S10}$ (Photovac International, Inc., Deer Park, N.Y.) equipped with a $10-\mathrm{cm}$, $10 \%$ SE-30 on an 80/100 mesh chromosorb column. With a carrier gas (zero grade air) flow rate of $17 \mathrm{~mL} / \mathrm{min}$, TCE eluted at 1.2 minutes and PCE eluted at 2.8 minutes. Detector response was recorded as peaks on a horizontal baseline using

Table 3. Nested design of sampling and analysis for ShallowTray medium temperature air stripping experiment.

\begin{tabular}{|c|c|c|c|c|c|c|c|c|}
\hline \multirow{2}{*}{$\begin{array}{l}\text { Type of sample } \\
\text { or analysis } \rightarrow\end{array}$} & \multicolumn{7}{|c|}{ Typical trial } & \multirow{2}{*}{$\begin{array}{c}\text { Totals } \\
\text { (per each type, } \\
\text { VOC and TPH) }\end{array}$} \\
\hline & & flue & & & $\mathcal{G C l}$ & & $Q C$ & \\
\hline Number & 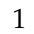 & 1 & 1 & & 1 & & 1 & $7 \times 8=56$ \\
\hline Number of analyses & 3 & 3 & 3 & 3 & 3 & 3 & 3 & $21 \times 8=168$ \\
\hline
\end{tabular}


a strip chart recorder. Concentrations were established by comparison of sample peak heights to aqueous standard peak heights. Combined standards (TCE and PCE) were prepared using chromatography grade reagents and serial dilution techniques.

TPH samples were collected in the 2-L Pyrex separatory funnels used for analysis, acidified with $\mathrm{HCl}$ to $\mathrm{pH} 2$ within 30 minutes and analyzed within 4 hours of collection. TPH concentration was determined by fluorocarbon-113 solvent extraction followed by infrared spectrophotometer analysis (EPA Method 418.1, U.S. EPA 1978). Infrared analysis was performed with a Foxboro Company (East Bridgewater, Mass.) MIRAN-1FF infrared spectrophotometer absorbance measurements were at a fixed wavelength of $3.48 \mu \mathrm{m}$. $\mathrm{TPH}$ concentrations were established by comparing sample absorbances to standard absorbances. Diesel fuel was used as the TPH standard since GC/MS analysis indicated the majority of hydrocarbons to be in this range. A stock standard was prepared by pipetting a known mass of diesel fuel into a known volume of spectral-grade fluorocarbon-113. Working standards were prepared by serial dilution of the stock standard with spectral-grade fluorocarbon-113. The 1-L samples were extracted with $100 \mathrm{~mL}$ of solvent, resulting in a sample concentration factor of $\times 10$. TPH concentrations were calculated with this formula:

$$
\mathrm{TPH}(\mathrm{ppm})=\frac{R \times D}{V}
$$

where $R=$ concentration of TPH as determined from calibration curve

$D=$ extract dilution factor $(0.1)$

$V=$ volume of sample.

Method detection limit and accuracy were greatly enhanced by preparing sample extracts that were 10 times the actual sample concentration, and by collecting samples directly into the separatory funnels used for extraction.

\section{Analytical precision and accuracy}

Method detection limits (MDLs) were determined according to APHA (1992). Practical quantitation limits (PQLs) were also used so that results could be directly compared to results produced by different laboratories. PQLs were calculated as five times the respective MDLs and represent practical and routinely achievable detection limits with a relatively good certainty that any reported value is reliable (APHA 1992).
A field blank, laboratory blank, and spiked duplicate sample or calibration check standard were analyzed with every group of six VOC or TPH samples. All field and laboratory blanks were below the PQL. Calibration check standard concentrations remained within \pm two times the standard deviation of the calibration standard ranges, i.e., within accepted analytical standards (APHA 1992). Duplicate VOC samples were collected during trials 5 and 9 for the purpose of spiking them with aliquots of standards. During TPH sampling and analysis, known additional samples were created during trials 5, 6 and 9 by adding a known mass of diesel fuel to $1 \mathrm{~L}$ of ultrafiltered water. The percentage of spiked standard or known addition recovered indicated the relative analytical precision and verified the absence of matrix effects. All percentage recoveries were within the $70-120 \%$ acceptance limits established by APHA (1992).

\section{Analysis of hydrocarbons \\ in air stripper off-gas}

Real-time measurements of total hydrocarbons in the air stripper off-gas were made during trials 3-6. Analysis was made with a model 51 Total Hydrocarbon Analyzer (Thermo Environmental Instruments, Inc., Franklin, Massachusetts) fitted with a heated flame-ionization detector (FID). A brass sampling tube was fitted into the off-gas stack, and a heated sample line conducted flow from the sampling tube to the analyzer. The sample line and analyzer were heated to $\geq 200^{\circ} \mathrm{C}$ $\left(\geq 392^{\circ} \mathrm{F}\right)$ to prevent condensation of the $100 \%$ humidity off-gas. The detector signal was recorded on a strip chart. The analyzer was calibrated according to the manufacturer's specifications using a 100-ppm TCE calibration gas standard. Total off-gas hydrocarbons were therefore measured "as TCE" because TCE made up $\geq 75 \%$ of the liquid hydrocarbons entering the stripper. The model 51 detects concentrations on a volume per volume basis; therefore the data were converted to mass per volume as follows:

$$
\begin{aligned}
\text { Hydrocarbons }\left(\frac{\mathrm{g}}{\mathrm{m}^{3}}\right) & =\left(\frac{\mathrm{L}}{\mathrm{m}^{3}} \mathrm{TCE}\right)^{A} \\
& \times\left(\frac{1 \mathrm{~mole} \mathrm{TCE}^{B}}{24.5 \mathrm{~L}}\right) \\
& \times\left(\frac{131 \mathrm{gTCE}^{C}}{1 \mathrm{~mole} \mathrm{TCE}^{-}}\right)
\end{aligned}
$$


where $A=$ ppm hydrocarbons as measured by model 51 analyzer

$B=$ volume of 1 mole of TCE gas at standard temperature and pressure

$C=$ molecular weight of TCE.

The 1-50 ppm or 1-100 ppm detection scales were used when the liquid flow to the air stripper was $18.9 \mathrm{~L} / \mathrm{min}$ and $75.7 \mathrm{~L} / \mathrm{min}$, respectively. Analyzer accuracy was $\pm 2 \%$ of scale.

\section{RESULTS AND DISCUSSION}

\section{Hydrocarbon mass balance}

Comparison of off-gas hydrocarbon loadings to liquid hydrocarbon loadings indicates that 100 $\pm 5 \%$ of the hydrocarbons entering the stripper were accounted for in the off-gas or effluent liquid. The sources of standard error in the mass balance estimate are 1) the analyzer accuracy of $\pm 2 \%$ of scale, 2) the error inherent in measuring TCE, PCE and paraffin hydrocarbons with an in- strument calibrated to TCE only, 3) the combined sampling and analytical error in TCE, PCE and TPH liquid concentrations, 4) the assumption of standard temperature and pressure, and 5) the measurement of air flow rate. The near $100 \%$ mass balance of hydrocarbons indicates that hydrocarbon removal in the ShallowTray unit was in fact by mass transfer to the off-gas and not by other phenomena (e.g., sorption, biodegradation).

\section{VOC removal}

A graphic summary of all VOC removal data is shown in Figures 3 and 4. Trial data are plotted in the same sequence in which trials were conducted, from left to right. The analytical practical quantitation limits (PQLs) are exceptionally low, just $0.625 \mathrm{ppb}$ for TCE and $0.543 \mathrm{ppb}$ for PCE. Despite such low quantitation limits, however, treatment efficiency was so high that effluent concentrations were routinely below them, particularly for PCE.

Influent TCE and PCE concentrations varied over 16-ppm and 6-ppm ranges (respectively),

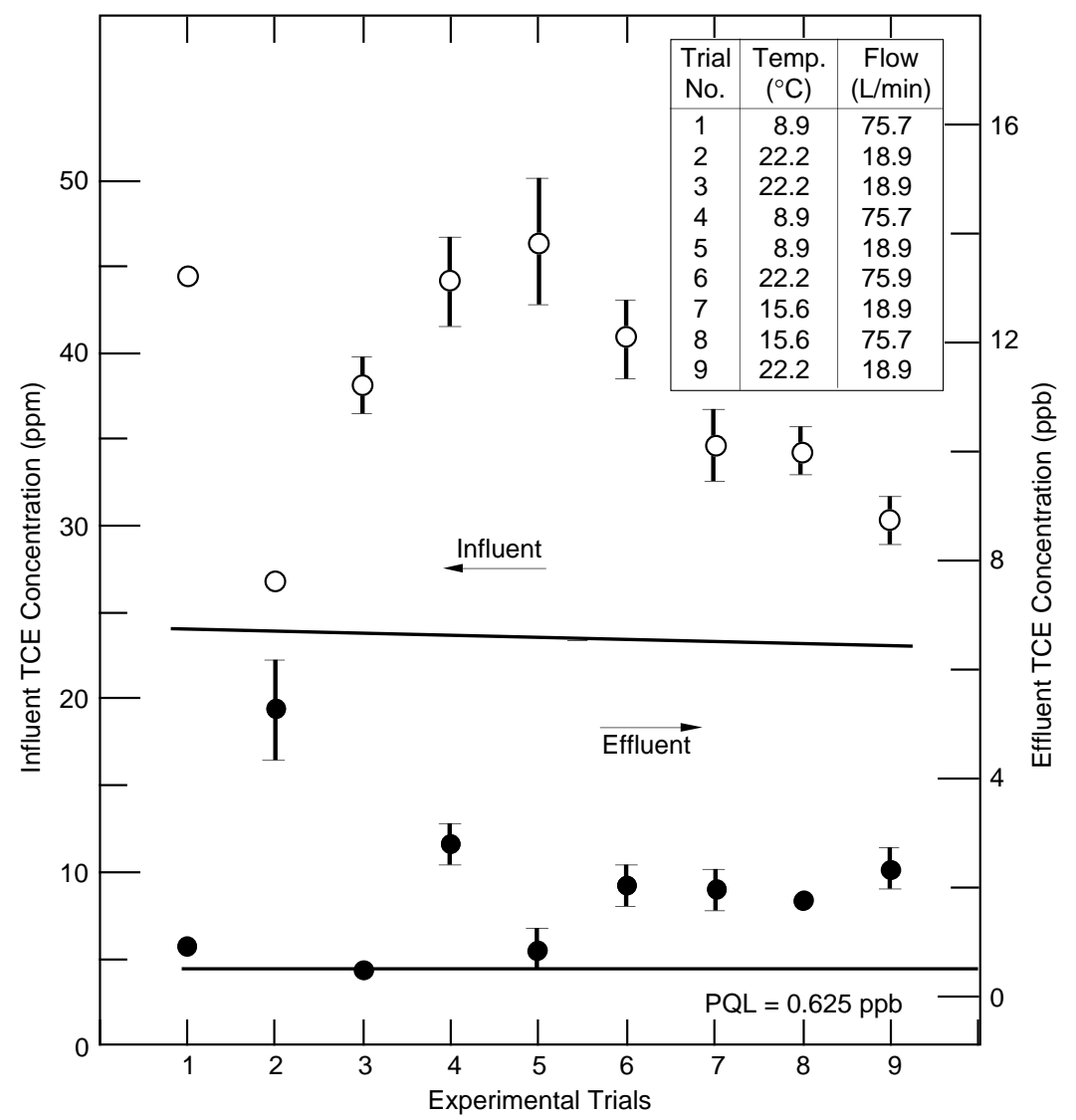

Figure 3. TCE pre-treatment and post-treatment concentrations for all experimental trials. 


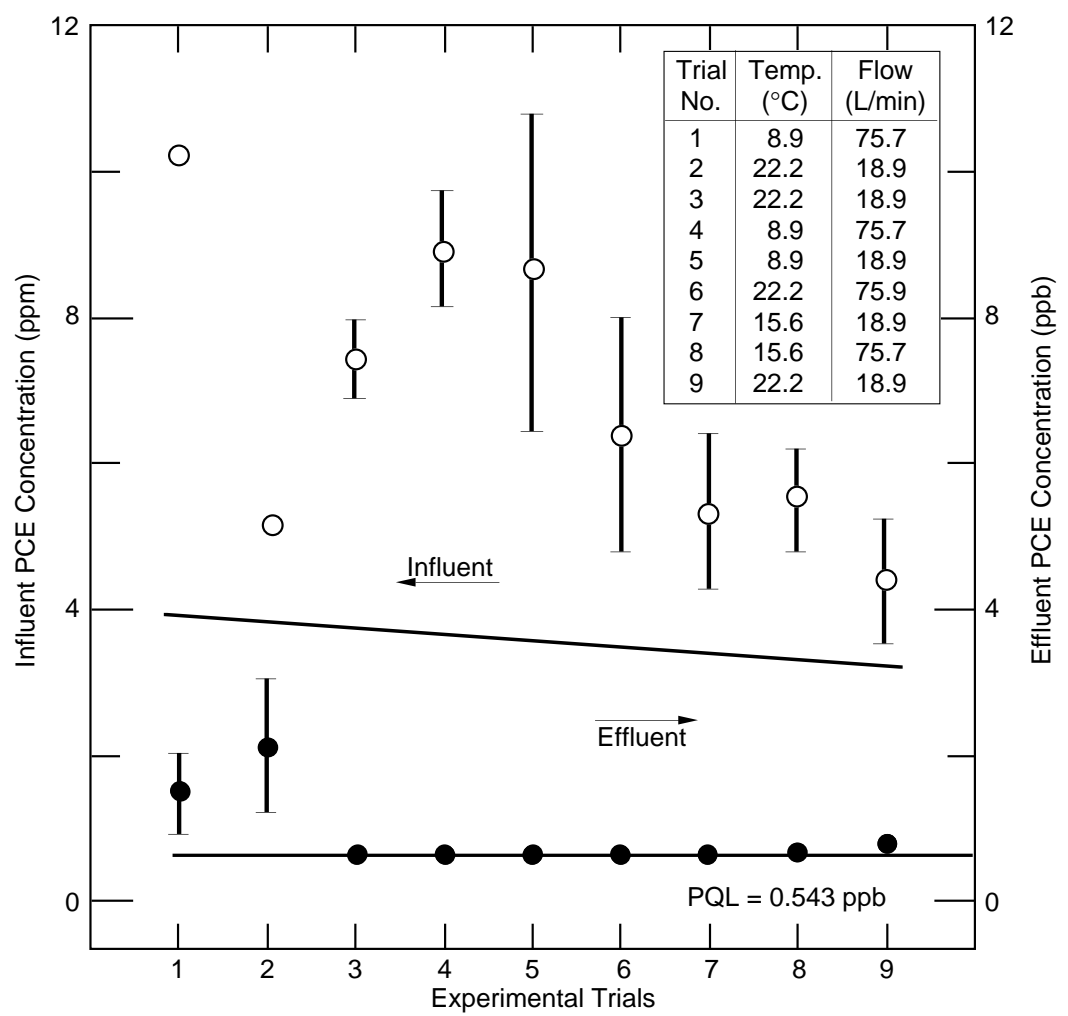

Figure 4. PCE pre-treatment and post-treatment concentrations for all experimental trials.

while effluent concentrations varied over 5-ppb and 2-ppb ranges (respectively). This trend suggests that VOC removal was independent of influent concentration. Mass transfer of VOCs was therefore controlled by the contaminants' properties and not the concentration gradient between liquid and gas phases, as expected, because of the high Henry's law constants and relatively low solubility of TCE and PCE in water. Another trend observed was the decrease of influent TCE and PCE concentrations over time, which is most likely a result of the treated water being recycled to the ice well where the contaminant concentrations for subsequent trials could have been slightly diluted. The higher than average influent sample variabilities for trials 5 and 6 resulted from freeze/thaw effects on some process water exposed to overnight temperatures below $0^{\circ} \mathrm{C}$ (all unit processes other than the equalization tank and ShallowTray stripper were outdoors). The treatment process procedures were modified to reduce the freeze/thaw effects. The effectiveness of the modifications is apparent in the de- creasing influent sample variabilities of trials 7,8 and 9. Effluent sample variability is consistently low after the initial equilibrium trials (trials 1,2).

The percentages of VOCs removed during all main trials are listed in Table 4. Student's $t$-test comparisons showed no significant difference between mean removals at all factor level combinations, at a $95 \%$ confidence interval. The efficiency

Table 4. VOC removals (\% removed) by ShallowTray air stripping achieved at three liquid temperatures and two liquid flow rates.

\begin{tabular}{ccccc} 
& & \multicolumn{3}{c}{ Liquid temperature } \\
\cline { 3 - 5 } Flow rate & VOC & $8.89{ }^{\circ} \mathrm{C}$ & $15.56^{\circ} \mathrm{C}$ & $22.2^{\circ} \mathrm{C}$ \\
\hline & TCE & $99.9978 \%$ & $99.9942 \%$ & $\begin{array}{c}99.9984 \% \\
(99.9918 \%)\end{array}$ \\
& & & & $99.993 \%$ \\
$18.9 \mathrm{~L} / \mathrm{min}$ & PCE & $99.9935 \%$ & $99.9927 \%$ & $(99.982 \%)$ \\
& & & & $99.9947 \%$ \\
$75.7 \mathrm{~L} / \mathrm{min}$ & TCE & $99.9936 \%$ & $99.9946 \%$ & \\
& & $(99.9918 \%)$ & & $99.9914 \%$ \\
& & $99.9942 \%$ & $99.9893 \%$ & \\
\hline
\end{tabular}

( ) duplicate trial results 
of the ShallowTray aerator at these flow rates is so high that $>99.99 \%$ reductions of VOC concentrations were achieved independent of liquid temperature and influent concentrations as high as $46.2 \mathrm{ppm}$ TCE and $10.8 \mathrm{ppm}$ PCE. All factor level combinations produced an effluent water with TCE and PCE concentrations below the EPA maximum contaminant levels (MCLs) of $5 \mathrm{ppb}$.

\section{Estimation of VOC liquid mass transfer coefficients}

Contaminant property effects on ShallowTray stripping efficiency were determined by comparing overall liquid mass transfer coefficients $\left(K_{\mathrm{L}} a\right)$ derived empirically from this research to published values for other types of air stripping systems. The rate of transfer of a volatile compound from water to air is generally proportional to the difference between the existing concentration and the equilibrium concentration of the compound in solution. The relationship is expressed as a modification of Fick's law:

$$
M=K_{\mathrm{L}} a\left(C_{\mathrm{L}}^{*}\right)-C_{0}
$$

where $M=$ mass of substance transferred per unit time and volume ( $\mathrm{mg} / \mathrm{min} \mathrm{L}$ )

$K_{\mathrm{L}}=$ overall liquid mass transfer coefficient $(\mathrm{m} / \mathrm{min})$

$a=$ effective mass transfer area $\left(\mathrm{m}^{2} / \mathrm{m}^{3}\right)$

$C_{\mathrm{L}}^{*}=$ liquid phase conc. in equilibrium with the gas phase conc. (mg/L)

$C_{0}=$ bulk phase (existing) liquid concentration $(\mathrm{mg} / \mathrm{L})$

The mass transfer coefficient $K_{\mathrm{L}}$ is a function of the properties of the compound being stripped (solubility, partial pressure and diffusivity), the physical characteristics of the air stripping equipment, and the temperature and flow rate of the liquid (Hess et al. 1983). The effective area $a$ represents the total air/water interface area created in the stripper and is a function of the air stripping equipment. The conventional approach assumes that the effective area is too difficult to estimate by itself and is evaluated with $K_{\mathrm{L}}$ as a single constant, $K_{\mathrm{L}} a$. The liquid phase equilibrium concentration $C_{L}^{*}$ is determined by applying Henry's law constant. The dimensionless Henry's law constant $\left(H_{\mathrm{c}}\right)$ is essentially the ratio of mass of contaminant in the gas phase at equilib- rium to the mass of contaminant in the liquid phase at equilibrium. By assuming that $100 \%$ of the liquid phase contaminants removed were transferred to the gas phase (a good assumption based on the near 100\% mass balance from offgas hydrocarbon measurements), the mass of contaminant in the gas phase is therefore known and the mass of contaminant in the liquid phase at equilibrium can be estimated as

$$
C_{\mathrm{G}}^{*} / C_{\mathrm{L}}^{*}=H_{\mathrm{C}} .
$$

Assuming $C_{\mathrm{G}}=C_{G}^{*}$ and rewriting, yields

$$
\mathrm{C}_{\mathrm{G}} / \mathrm{H}_{\mathrm{C}}=\mathrm{C}_{\mathrm{L}}^{*} \text {. }
$$

Since all the VOCs are transferred to the air, $M=$ $C_{\mathrm{G}}$ and eq 3 can be rewritten to solve for $K_{\mathrm{L}} a$ in this manner:

$$
K_{\mathrm{L}} a=\frac{C_{\mathrm{G}}}{\left(C_{\mathrm{L}}^{*}-C_{0}\right)}
$$

The results of evaluating $K_{\mathrm{L}} a$ using eq 5 and 6 and data from this research for TCE and PCE are summarized in Table 5. Because Henry's law constant varies with liquid temperature, three $K_{\mathrm{L}} a$ values were determined (one at each temperature) for each VOC. As expected the $K_{\mathrm{L}}$ a values at both flow rates for a given temperature were also calculated and each pair were found to be equal. Values derived from this research show good agreement with those published by McCarty (1983). Mass transfer of both contaminants, in fact, indicate that the ShallowTray strippers are very competitive with packed towers in removal efficiency per unit volume.

\section{TPH removal}

A graphic summary of all TPH removal data is shown in Figure 5. Trial data are plotted in the

\begin{tabular}{|c|c|c|c|c|c|}
\hline \multirow{2}{*}{$\begin{array}{c}\text { Temperature } \\
\left({ }^{\circ} \mathrm{C}\right)\end{array}$} & \multicolumn{2}{|c|}{ TCE } & \multicolumn{2}{|c|}{ PCE } & \multirow{2}{*}{$\begin{array}{c}\text { McCarty (1983) } \\
\left(\sec ^{-1}\right)\end{array}$} \\
\hline & $H_{C}^{*}$ & $K_{L}^{a}\left(\sec ^{-1}\right)$ & $H_{C}{ }^{+}$ & $K_{L}^{a}\left(\sec ^{-1}\right)$ & \\
\hline 22.2 & 0.375 & 0.01 & 0.586 & 0.024 & $0.025^{* *}$ \\
\hline 15.56 & 0.384 & 0.0104 & 0.599 & 0.025 & $0.0009^{t+}$ \\
\hline 8.89 & 0.393 & 0.0108 & 0.613 & 0.026 & $0.007^{* * *}$ \\
\hline
\end{tabular}
same sequence in which trials were conducted,

Table 5. Estimate of mass transfer coefficients for ShallowTray stripping of TCE and PCE at three liquid temperatures.

* source-U.S. EPA 1990

${ }^{\dagger}$ source-Munz and Roberts 1979

** countercurrent tower (VOC stripping at $20^{\circ} \mathrm{C}, Q=6600 \mathrm{~L} / \mathrm{min}$ )

${ }^{+\dagger}$ cross flow tower (VOC stripping, $Q=19,800 \mathrm{~L} / \mathrm{min}$ )

*** mechanical aeration basin (VOC stripping, $Q=2640 \mathrm{~L} / \mathrm{min}$ ) 


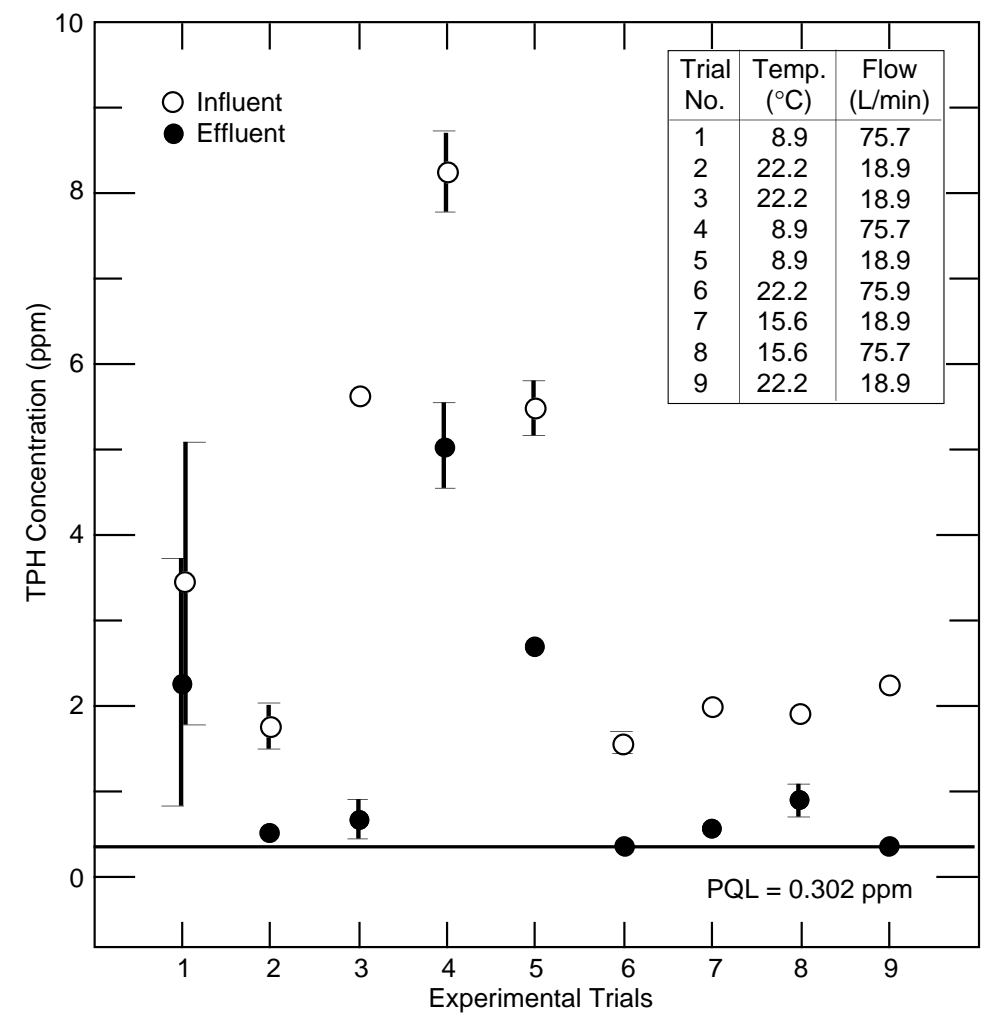

Figure 5. TPH pre-treatment and post-treatment concentrations for all experimental trials

from left to right. The analytical PQL is low, just $0.3 \mathrm{ppm}$ of TPH in water. Effluent concentrations from several trials were at or just below the PQL.

The most significant removal trend was the link between influent and effluent concentrations. Although a significant amount of TPH was stripped in every trial, the effluent concentrations were greater (or lesser) than the mean when influent concentrations were greater (or lesser) than the mean. Unlike VOC stripping, effluent TPH concentration appears to be dependent on influent TPH concentration. The driving force for TPH is $\left(C_{L}^{*}-C_{0}\right)$, irrespective of the compound of interest; properties of the compound are factored into the value for $K_{\mathrm{L}}$. The trend of decreasing influent TPH concentration over time is similar to that observed for VOC concentrations and is also due to dilution of contaminated source water with treated recycled water. Student's $t$-tests performed between each factor level combination showed all removals to be significantly different at the 95\% confidence interval. The percentage of TPH removal during each experiment was calculated as:

$R=\frac{(\text { avg. influent conc. }- \text { avg. effluent conc. })}{\text { avg. influent conc. }} \times 100$.
When the data from eq 7 are graphed as a function of the two factors, the plot looks like Figure 6. Six data points result from the six possible factor level combinations, and there are two additional data points for the duplicate trials. This graph shows the strong linear relationship between removal and increasing liquid temperature, and because there are three levels (data points) for the temperature factor the sums of squares can be decomposed into polynomial effects (Ross 1985). Polynomial decomposition calculations confirm the relationship between TPH removal and liquid temperature to be 300 times more linear than quadratic. Although a quadratic vs. linear relationship between removal and liquid flow rate cannot be ascertained from just two data points, a reasonable assumption is that removal will reach some asymptotic minimum vs. increasing flow rate at a given liquid temperature.

A first-order regression was performed on the results from eq 7, yielding a TPH removal predictor equation:

$$
R_{\mathrm{p}}=2.61\left(T_{\mathrm{L}}\right)-0.22\left(Q_{\mathrm{L}}\right)+33.72
$$


where $R_{\mathrm{P}}=$ predicted future value of $R$

$T_{\mathrm{L}}=$ influent liquid temperature $\left({ }^{\circ} \mathrm{C}\right)$

$Q_{\mathrm{L}}=$ influent liquid flow rate (liters/ minute).

According to eq 8, a one-degree increase in temperature will result in a $2.61 \%( \pm 0.25 \%)$ increase in $\mathrm{TPH}$ removal, and a unit increase in liquid flow rate will decrease TPH removal by $0.22 \%$ $( \pm 0.05 \%)$. The correlation coefficient for this equation, $r^{2}$, equals 0.972 . At the low flow rate $(18.9 \mathrm{~L} /$ min), eq 8 predicts that $100 \% \mathrm{TPH}$ removal will occur at $27.0^{\circ} \mathrm{C}$. However, as in the case for decreasing removal vs. flow rate, removal can reasonably be expected to reach some asymptotic maximum as temperature increases. This predicted maximum removal temperature is in good agreement with vapor pressure data reported in the literature for diesel range hydrocarbons (decane, $\mathrm{C}_{10} \mathrm{H}_{22}$, through octacosane, $\mathrm{C}_{28} \mathrm{H}_{94}$ ). Vapor pressure of a hydrocarbon-saturated liquid was estimated (Franks 1966) to be roughly atmospheric at $25^{\circ} \mathrm{C}$ for the $\mathrm{C}_{10}$ through $\mathrm{C}_{20}$ hydrocarbons, which make up roughly two-thirds of the diesel range. A discussion of phase equilibria in water-hydrocarbon systems contained in API (1976) refers to Franks (1966) and others in defining $25^{\circ} \mathrm{C}$ as the "maximum temperature for the water-rich phase" of water-hydrocarbon systems containing diesel range paraffins $\left(\mathrm{C}_{10}\right.$ through $\mathrm{C}_{16}$ ). In other words, equilibrium between the non-

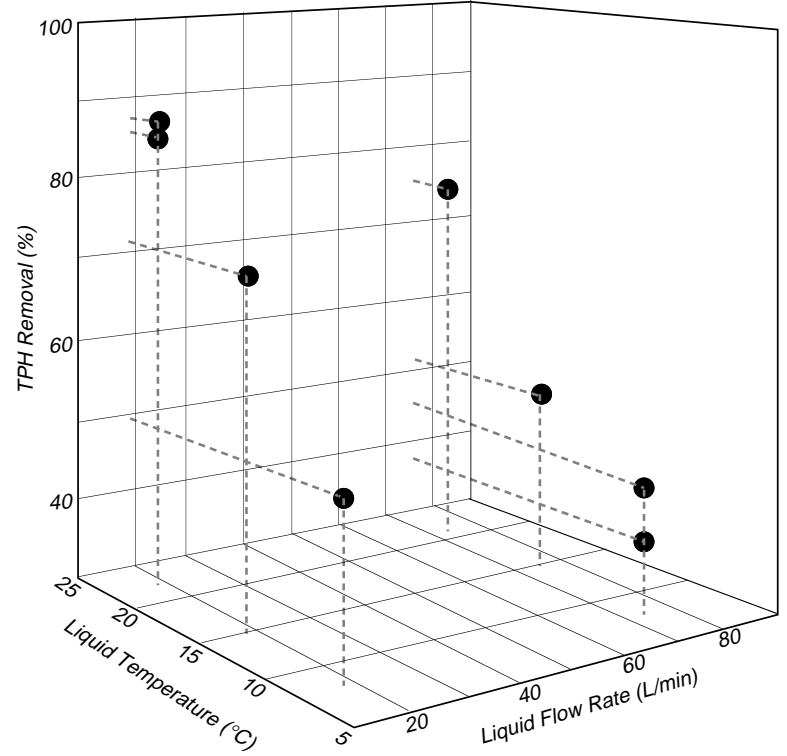

Figure 6. TPH stripping performance (percentage removed) at three liquid temperatures and two flow rates.

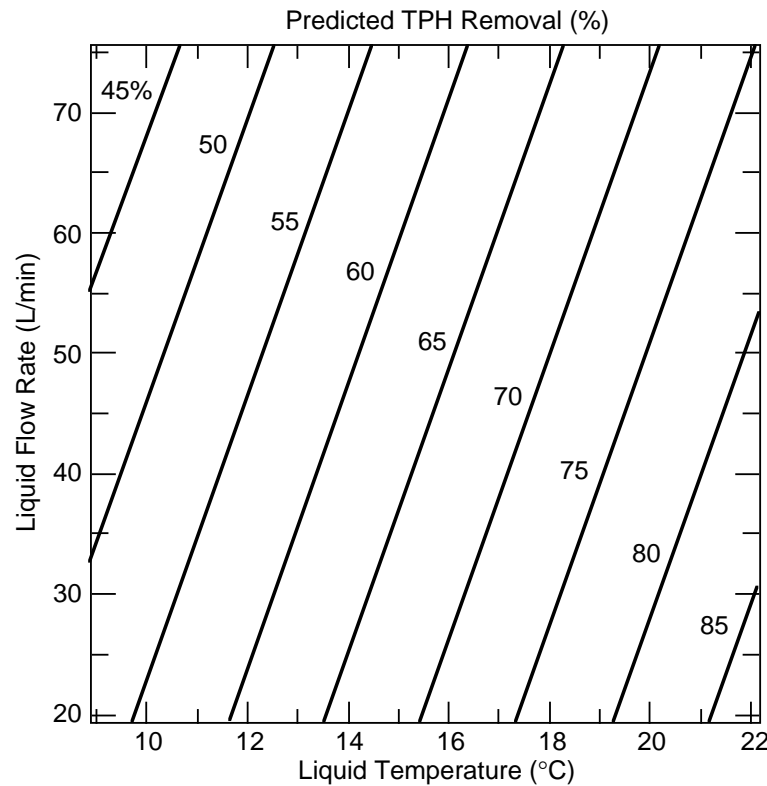

Figure 7. Predicted response surface for TPH removal vs. liquid temperature and flow rate.

saturated gas phase and the liquid phase containing the highest possible concentration of soluble $\mathrm{C}_{10}$ through $\mathrm{C}_{16}$ hydrocarbons is expected at atmospheric pressure and $25^{\circ} \mathrm{C}$. The model (eq 8) predicts this will occur in the ShallowTray stripper at atmospheric pressure and $27^{\circ} \mathrm{C}$. Equation 8 is shown graphically as a predicted response surface in Figure 7. When lines are extended from the $x$ and $y$ axes at known values of liquid temperature and flow rate, they will intersect nearest to the diagonal line that predicts the percent of $\mathrm{TPH}$ removal.

\section{Influence of experimental factors on ShallowTray performance}

The statistical estimate of the main effects and factor interactions during ShallowTray stripping of TCE, PCE and TPH was determined by analysis of variance (ANOVA) of removal data. A summary of experimental parameter contributions to contaminant removal is shown in Table 6. A contribution below $15 \%$ is generally accepted as statistically insignificant.

The ANOVA results show that liquid flow rate did not affect VOC removal, but liquid temperature was the most significant factor influencing TCE removal and somewhat significant to PCE removal. The interaction of the two factors was the dominant factor influencing PCE removal but was only somewhat significant to TCE removal. The interaction and error terms also increase with 
Table 6. Contribution of experimental factors to ShallowTray stripping efficiency of TCE, PCE and TPH (\% contribution as determined by analysis of variance [ANOVA]).

\begin{tabular}{|c|c|c|c|}
\hline Parameter & TCE $(\%)$ & PCE $(\%)$ & TPH $(\%)$ \\
\hline Flow rate & 2.8 & 0.0 & 14.9 \\
\hline Liquid temperature & 64.3 & 15.7 & 74.3 \\
\hline Interaction & & & \\
\hline (Flow $\times$ temp.) & 15.6 & 60.1 & 2.4 \\
\hline Total error & 17.3 & 24.2 & 8.4 \\
\hline Sampling error & 3.24 & 4.24 & 10.4 \\
\hline Analytical error & 6.56 & 8.86 & 6.3 \\
\hline Unexplained error ${ }^{*}$ & 7.5 & 11.1 & 0 \\
\hline
\end{tabular}

* Total error $-($ sampling + analytical error $)=$ unexplained error

the compound's volatility (PCE is slightly more volatile than TCE).

The VOC error terms are both $>15 \%$, indicating that experimental error or unexplained variability was unacceptably high. Approximately $45 \%$ of this unexplained variability was due to analytical and sampling error. The mean relative standard deviation (RSD) of combined analytical and sampling variability is $9.8 \%$ (TCE) and $13.1 \%$ (PCE) (see Table 6). The majority of the unexplained variability, $55 \%$, is due to factors that were not fully controlled during the experiments, in particular the VOC influent concentrations. Because the highly effective VOC stripping produced consistent effluent concentrations over a narrow range, the wide range of influent concentrations (which were not a function of the experimental factors but of treatment process handling) created a large variability in VOC removals which was independent of the controlled variables. This "process handling" variability is particularly noticeable in the duplicate trial data. Influent VOC concentrations of the two pairs of duplicate trials differed from 1.1-36.8\% RSD. Effluent concentration variability was even greater (20.1-84.1\% RSD) due to the extremely low concentrations that exaggerate even the smallest of differences. The net result of this uncontrolled error was to make it impossible to correlate the VOC data into a VOC removal prediction model.

The statistical estimate of the main effects and factor interactions during ShallowTray stripping of TPH was also determined by analysis of variance (ANOVA) of removal data $(R)$. A summary of experimental parameter contributions to TPH removal is shown in the right-hand column of Table 6. A contribution below $15 \%$ is generally accepted as statistically insignificant. Liquid flow rate was somewhat significant to TPH removal but the main controlling factor was liquid temperature, which contributed to $74.3 \%$ of the TPH stripping differences observed at the six factor/ level combinations. The interaction of the two experimental factors was insignificant and the error or unexplained variability was low $(8.4 \%)$. The low error term indicates that all variables significant to TPH stripping were controlled during the experiment.

\section{Treatment process \\ power requirements}

Total treatment costs involve many variables, and the specific capital, operating and maintenance costs of the batch process presented here would be difficult to use for predicting large scale or continuous flow treatment systems. However, it is instructive to examine the power consumed per volume of water treated as stripping and water heating components. Power consumption rates can be compared between widely different stripper types and treatment methods to give a rough economic comparison for initial design choices.

Air stripper power consumption data were plotted, yielding an inverse relationship between power consumed $(\mathrm{kW} / 3785 \mathrm{~L}$ treated) and flow rate (Fig. 8). The equation describing this relationship is the predictor equation for stripping (only) power requirements:

$$
\frac{\mathrm{kW}}{3785 \mathrm{~L} \text { treated }}=\left[0.02\left(Q_{\mathrm{L}}\right)+0.0157\right]^{-1}
$$

where $Q_{\mathrm{L}}=$ liquid flow rate $(\mathrm{L} / \mathrm{min})$.

Water was heated for treatment during six trials, each time raising a different volume from a different initial temperature to either $15.56^{\circ} \mathrm{C}$ or $22.2^{\circ} \mathrm{C}$. The kilowatts $(\mathrm{kW})$ required to heat the liquid (using the equipment previously described) were recorded. When these data were plotted as $\mathrm{kW} /{ }^{\circ} \mathrm{C}$ increase vs. liters of water heated, the linear relationship was described by a first-order regression:

$$
\frac{\mathrm{kW}}{{ }^{\circ} \mathrm{C} \text { increase }}=\left[0.0034\left(V_{\mathrm{L}}\right)-4.035\right]
$$

where $V_{\mathrm{L}}=$ liquid volume $(\mathrm{L})$

From eq 10 it can be seen that when $V_{\mathrm{L}}=3785 \mathrm{~L}$ (1000 gal.), $8.83 \mathrm{~kW} / \Delta^{\circ} \mathrm{C}$ are required. This variable can be added to the equation for stripping 


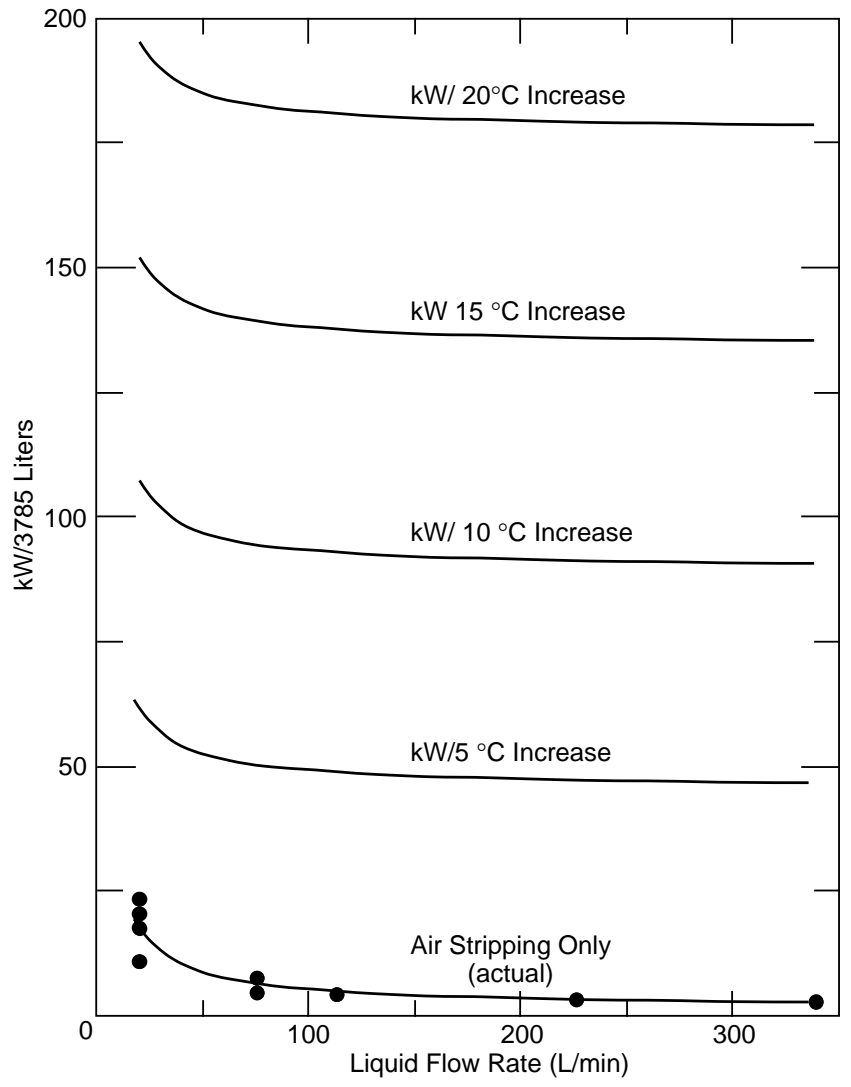

Figure 8. Stripping and heating power requirements vs. liquid flow rate, ShallowTray medium temperature process.

power requirements to yield a total power requirement per volume per $\Delta^{\circ} \mathrm{C}$. The resulting predictor equation for stripping and heating power requirements per volume of liquid treated is

$$
\begin{aligned}
\frac{\mathrm{kW}}{(3785 \mathrm{~L} \text { treated })} & =\left[0.002\left(Q_{\mathrm{L}}\right)+0.0157\right]^{-1} \\
& +8.83\left(\Delta^{\circ} \mathrm{C}\right)
\end{aligned}
$$

A simple example can illustrate the use of eq 8 and 11.

Example: What would be the predicted treatment power requirements for stripping a certain volume of water (at $8.89^{\circ} \mathrm{C}$ ) contaminated with 5-10 ppm diesel-range petroleum hydrocarbons (as TPH) and 30-50 ppm VOCs (with Henry's law constant values $\geq 0.003$ ) using a ShallowTray series 2600 air stripper, assuming a liquid flow rate $75.7 \mathrm{~L} /$ min (20 gpm) to the stripper and treatment goals of $99 \%$ VOC removal and $90 \% \mathrm{TPH}$ removal?
Step 1-Assume that at $90 \% \mathrm{TPH}$ removal, $>99 \%$ VOC removal will occur (i.e., TPH removal controls total removal). Calculate required treatment temperature by rearranging eq 8 to solve for $T_{\mathrm{L}}$ :

$$
\begin{aligned}
T_{\mathrm{L}} & =\frac{\left[R_{\mathrm{p}}+0.22\left(Q_{\mathrm{L}}\right)-33.72\right]}{2.61} \\
& =\frac{[90+0.22(75.7)-33.72]}{2.61} \\
& \therefore T_{\mathrm{L}}=27.9^{\circ} \mathrm{C}\left(82.3^{\circ} \mathrm{F}\right)
\end{aligned}
$$

Step 2-Calculate $\Delta^{\circ} \mathrm{C}$, using $T_{\mathrm{L}}$ and given initial temperature, $T_{\mathrm{i}}=8.89^{\circ} \mathrm{C}: \Delta^{\circ} \mathrm{C}$ $=T_{\mathrm{L}}-\mathrm{T}_{\mathrm{i}}=27.9^{\circ} \mathrm{C}-8.89^{\circ} \mathrm{C}=19^{\circ} \mathrm{C}$

Step 3-Use $Q_{\mathrm{L}}$ and $\Delta^{\circ} \mathrm{C}$ in eq 11 to predict power requirement per unit volume of water to heat and air strip as required:

$$
\begin{aligned}
{[0.002(75.7 \mathrm{lpm})} & +0.0157]^{-1}+8.83\left(19^{\circ} \mathrm{C}\right) \\
& =\frac{174 \mathrm{~kW}}{(3785 \mathrm{~L} \text { treated })}
\end{aligned}
$$

This example shows that a low flow rate and significant quantity of power is required for treating TPH contaminated water to a high standard. When a typical cost per kilowatt-hour is assumed (e.g., $\$ 0.08 / \mathrm{kWh}$ ), the example treatment cost is much lower than literature values for steam or high temperature air stripping (HTAS) costs (Fleming 1989 and EPA 1990). The example does not consider emission controls, contaminant destruction, or disposal costs. However, the batch mode employed for this research is very inefficient and could easily be made more economical using standard insulation techniques and a continuous or in-line heating operation. Many new remediation sites have a steam generation capability for carbon regeneration, soil washing and subsurface injection/extraction methods. Excess heat from these processes could be used for water heating, or steam use could be shared among several processes. The advantage of the medium temperature process described is that high quality steam is not required, and less heating energy than competing HTAS processes is needed regardless of the source. 


\section{SUMMARY AND CONCLUSIONS}

Air stripping experiments performed as part of this work demonstrated that diesel range petroleum hydrocarbons (TPH) can be effectively stripped from water in conjunction with VOCs at modest liquid flow rates and temperatures (using a tray-type air stripper). The batch process employed was capable of treating the contaminated source water to within discharge permit standards at a lower cost per volume treated than high temperature airstripping (HTAS) systems or high performance oil/water separation combined with air stripping.

VOC stripping efficiency did not appear to be affected by TPH stripping. High concentrations (40-50 ppm) of VOCs were reduced by $\geq 99.99 \%$ during all experiments, regardless of TPH concentration, liquid flow rate or temperature. VOC removals were so consistently high that no statistically discernible trends were observed as a function of liquid flow rate and temperature. Mass transfer of VOC from liquid to gas phase was driven by the contaminant's physical and thermodynamic properties, not the concentration gradient. Mass transfer coefficients $\left(K_{\mathrm{L}} a\right)$ were determined for TCE and PCE using removal data, and these showed good agreement with published values of VOC mass transfer coefficients in packedtower air strippers.

Significant amounts of TPH were stripped during all experiments, but variations in liquid temperature affected TPH stripping more than variations in flow rate. The low residual error associated with the TPH removal data indicates that liquid temperature and flow rate were the only significant factors controlling TPH stripping efficiency. Mass transfer of TPH from liquid to gas phase was driven by concentration gradient; however, liquid heating affected the contaminants' thermodynamic properties sufficiently to improve removals to the $80-90 \%$ range. For similar liquid heating and ShallowTray air stripping applications, TPH removal can be predicted using the multilinear regression model (eq 8), or the TPH removal predicted response surface (Fig. 7). Equation 8 is probably only valid when predicting removals below $90 \%$, and removals above this level are expected to approach some asymptotic value as a function of liquid temperature and flow rate. The liquid temperatures predicted by eq 8 as necessary to achieve maximum ("100\%") $\mathrm{TPH}$ (diesel-range or paraffin hydrocarbons) removal, $27^{\circ} \mathrm{C}$ to $31.8^{\circ} \mathrm{C}$, are corroborated by pre- vious research, which indicates that water-rich paraffin hydrocarbon phases reach equilibrium with the gas phase at atmospheric pressure and $25^{\circ} \mathrm{C}$. A model to predict liquid heating and air stripping power requirements per volume of water treated was determined (eq 11), but is based only on the batch mode process used in this study. A significant advantage of the ShallowTray stripper appears to be the large air/water ratio it generates (100-900), in comparison to air/water ratios typical of counter-current packed towers (50-150) treating similar contaminant mass loadings. This high air/water ratio allows very effective mass transfer of VOCs/SVOCs over a relatively small surface area (just $2.8 \mathrm{~m}^{2}$ for the unit used in this research).

\section{RECOMMENDATIONS}

The ShallowTray air stripper was proven to be just as efficient at removing VOCs as packed tower systems. It also proved capable of treating heated water to strip significant fractions of petroleum hydrocarbons without fouling, based on achieving $100 \%$ ( \pm sampling and analytical error) mass balance of hydrocarbons. The medium temperature air stripping process appears to not only be effective but economically competitive with other processes. Remediation projects which require or already employ air stripping/solid phase adsorption for VOC removal from groundwater can be cost effectively retrofitted with a modest liquid heating capacity so that petroleum hydrocarbons can be removed concurrently with the VOCs. Additional research should be conducted to evaluate the effects of increased detention time, higher liquid temperatures and continuous mode treatment on TPH stripping efficiency. Detention time is easily increased in ShallowTray strippers by adding the modular trays, so that for essentially the same power requirements (i.e., operating costs) higher removals are achieved. The continuous mode, medium temperature process should also be used to treat other contaminated source waters in order to more fully explore the applications of the process.

\section{LITERATURE CITED}

APHA (1992) Standard Methods for the Examination of Water and Wastewater, 18th Edition. American Public Health Association, Washington, D.C. 
API (1976) Technical Data Book-Petroleum Refining, Chap. 9: Phase Equilibria in Water-Hydrocarbon Systems. American Petroleum Institute, Washington, D.C.

API (1983) Treatment Technology for Removal of Dissolved Gasoline Components from Ground Water. American Petroleum Institute, Washington, D.C., API Pub. 4369.

Boadway, D., and D.F. Lawler (1990) Technical and economic considerations in choosing among stripping, stripping with gas-phase adsorption, and liquid-phase adsorption. In Proceedings of the American Water Works Association Conference, Cincinnati, Ohio, June 17-21.

Borden, R.C., and C.-M. Kao (1992) Evaluation of ground water extraction for remediation of petroleum-contaminated aquifers. Water Environmental Research, 64: 28.

Crittenden, J.C., R.D. Cartright, B. Rick, S.R. Tang, and D. Perram (1988) Using GAC to remove VOCs from air stripper off-gas. Journal of the American Water Works Association, 80(5): 73.

Fleming, J.L. (1989) Volatilization technologies for removing organics from water. Noyes Data Corp., Park Ridge, New Jersey.

Franks, F. (1966) Solute-water interactions and the solubility behavior of long-chain paraffin hydrocarbons. Nature, 210(5031): 87.

Hackman, E.E., III (1978) Toxic organic chemicals-destruction and waste treatment. Noyes Data Corp., Park Ridge, New Jersey.

Hess, A.F., J.E. Dyksen, and H.J. Dunn (1983) Occurrence and Removal of Volatile Organic Chemicals from Drinking Water, Chap. 5, Control Strategy-Aeration Treatment Technique. American Water Works Association Research Foundation, Denver, Colorado.

Hewitt, A.D., P.H. Miyares, D.C. Leggett, and
T.F. Jenkins (1992) Comparison of analytical methods for determination of VOCs in soils. Environmental Science and Technology, 25(10): 1932.

Kavanaugh, M.C., and R.R. Trussell (1980) Design of aeration towers to strip volatile contaminants from drinking water. Journal of the American Water Works Association, 72(12): 684.

Lamarre, B. (1993) Selecting an air stripper-what to consider. The National Environmental Journal, July/Aug.

McCarty, P.L. (1983) Control of Organic Substances in Water and Wastewater, Chap. 9, Removal of Organic Substances from Water by Air Stripping. EPA600/8-83-011, U.S. EPA, Washington, D.C.

Munz, C., and P.V. Roberts (1979) Air-water phase equilibria of volatile organic solutes. Journal of the American Water Works Association, 79(5): 62.

Rose, D. (1994) DOD, DOE Clean-up efforts promising. Environmental Protection, 5(1): 58.

Ross, P.J. (1985) Taguchi Techniques for Quality Engineering. New York: McGraw Hill Book Co.

U.S. GAO (1992) Environmental Protection Issues. Transition Series Report no. GAO/OCG-93-16TR. U. S. General Accounting Office, Washington, D.C. U.S. EPA (1978) Methods for Chemical Analysis of Water and Wastes. U.S. Environmental Protection Agency, Washington, D.C.

U.S. EPA (1985) Handbook: Remedial Action at Waste Disposal Sites. EPA/625/6-85/006. U.S. Environmental Protection Agency, Washington, D.C.

U.S. EPA (1990) Basics of pump-and-treat ground water remediation technology. EPA/600/8-90/ 003. U.S. Environmental Protection Agency, Washington, D.C.

U.S. EPA (1991) Air stripping of aqueous solutions. EPA/540/2-91/022, U.S. Environmental Protection Agency, Washington, D.C. 


\section{REPORT DOCUMENTATION PAGE}

Public reporting burden for this collection of information is estimated to average 1 hour per response, including the time for reviewing instructions, searching existing data sources, gathering and maintaining the data needed, and completing and reviewing the collection of information. Send comments regarding this burden estimate or any other aspect of this collection of information, including suggestion for reducing this burden, to Washington Headquarters Services, Directorate for Information Operations and Reports, 1215 Jefferson Davis Highway, Suite 1204, Arlington, VA 22202-4302, and to the Office of Management and Budget, Paperwork Reduction Project (0704-0188), Washington, DC 20503.

\begin{tabular}{|l|l|l}
\hline 1. AGENCY USE ONLY (Leave blank) & 2. REPORT DATE & 3. REPORT TYPE AND DATES COVERED
\end{tabular}

March 1997

Stripping Volatile Organic Compounds and Petroleum Hydrocarbons

From Water by Tray Aeration

6. AUTHORS

David F. LaBranche and M. Robin Collins

7. PERFORMING ORGANIZATION NAME(S) AND ADDRESS(ES)

8. PERFORMING ORGANIZATION

REPORT NUMBER

Civil Engineering Department

University of New Hampshire

Special Report 97-6

Durham, NH 03824-3591

9. SPONSORING/MONITORING AGENCY NAME(S) AND ADDRESS(ES)

\section{USACRREL}

Hanover, NH 03755-1290

North East Environmental Products, Inc.

West Lebanon, NH 03784
10. SPONSORING/MONITORING AGENCY REPORT NUMBER

Environmental Research Group

University of New Hampshire

Durham, NH 03824

11. SUPPLEMENTARY NOTES

12a. DISTRIBUTION/AVAILABILITY STATEMENT

12b. DISTRIBUTION CODE

Approved for public release; distribution is unlimited.

Available from NTIS, Springfield, Virginia 22161

13. ABSTRACT (Maximum 200 words)

Volatile organic compounds (VOCs) and petroleum products are ubiquitous groundwater contaminants. Petroleum products, e.g., diesel fuel, contain a wide array of volatile, semivolatile, and long-chain hydrocarbon compounds. This research sought to determine whether air stripping can provide a site-specific treatment solution for petroleum-contaminated groundwaters and to document the abilities and limitations of tray-type (ShallowTray) air stripping technology. Full factorial experimental trials were conducted to determine the influence of inlet water flow rate and temperature on trichloroethylene (TCE), perchloroethylene (PCE) and total petroleum hydrocarbon (TPH) removal. As expected, TPH removal controlled air stripper performance, and liquid temperature affected removal more than flow rate. The mass transfer rate of TCE and PCE from water to air was controlled by the compound's volatility, while the TPH mass transfer rate was controlled by the compound's concentration gradient. Results indicate that economical air stripping of VOC and TPH compounds can be achieved using low liquid flow rates $(20-75 \mathrm{~L} / \mathrm{min})$ and medium liquid temperatures (16$28^{\circ} \mathrm{C}$ ) in tray-type air strippers.

\begin{tabular}{|c|c|c|c|}
\hline \multicolumn{4}{|l|}{ 14. SUBJECT TERMS } \\
\hline Air stripping & Diesel fuel & Modeling & Remediation \\
\hline Contamination & Groundwater & Petroleum & Tray-type air strippers \\
\hline $\begin{array}{l}\text { 17. SECURITY CLASSIFICATION } \\
\text { OF REPORT }\end{array}$ & $\begin{array}{l}\text { 18. SECURITY } \\
\text { OF THIS F }\end{array}$ & SIFICATION & $\begin{array}{l}\text { 19. SECURITY CLASSIFICATION } \\
\text { OF ABSTRACT }\end{array}$ \\
\hline UNCLASSIFIED & UNCL & FIED & UNCLASSIFIED \\
\hline
\end{tabular}

15. NUMBER OF PAGES 24

16. PRICE CODE

20. LIMITATION OF ABSTRACT

UL

Standard Form 298 (Rev. 2-89) Prescribed by ANSI Std. Z39-18 298-102 